\title{
Race Performance Prediction from the Physiological Profile in National Level Youth Cross-Country Cyclists
}

\author{
Gerardo Gabriel Mirizio ${ }^{1}$, Rodrigo Muñoz ${ }^{2}$, Leandro Muñoz ${ }^{3}$, Facundo Ahumada ${ }^{3}$ and Juan Del Coso ${ }^{4, *(D)}$ \\ 1 Muscle Cell Physiology Laboratory, Centre of Molecular Studies of the Cell, Institute of Biomedical Sciences, \\ Faculty of Medicine, Universidad de Chile, Santiago 8380000, Chile; gerardo.mirizio@ug.uchile.cl \\ 2 School of Kinesiology, Faculty of Medicine, Universidad Finis Terrae, Providencia, Santiago 7501015, Chile; \\ roquem_08@hotmail.com \\ 3 Department of Investigation and Development (I + D), International Endurance Group, \\ Córdoba 5009, Argentina; leandromartinmunoz@gmail.com (L.M.); fahumadacordoba@gmail.com (F.A.) \\ 4 Centre for Sport Studies, Rey Juan Carlos University, Fuenlabrada, 28942 Madrid, Spain \\ * Correspondence: juan.delcoso@urjc.es
}

check for updates

Citation: Mirizio, G.G.; Muñoz, R.; Muñoz, L.; Ahumada, F.; Del Coso, J. Race Performance Prediction from the Physiological Profile in National Level Youth Cross-Country Cyclists. Int. J. Environ. Res. Public Health 2021, 18, 5535. https://doi.org/10.3390/ ijerph18115535

Academic Editors: Ana Filipa Silva, Filipe Manuel Clemente and Daniele Conte

Received: 25 April 2021

Accepted: 18 May 2021

Published: 21 May 2021

Publisher's Note: MDPI stays neutral with regard to jurisdictional claims in published maps and institutional affiliations.

Copyright: (c) 2021 by the authors. Licensee MDPI, Basel, Switzerland. This article is an open access article distributed under the terms and conditions of the Creative Commons Attribution (CC BY) license (https:// creativecommons.org/licenses/by/ $4.0 /)$.

\begin{abstract}
Cross-country mountain biking is an Olympic sport discipline with high popularity among elite and amateur cyclists. However, there is a scarcity of data regarding the key determinants of performance, particularly in young cross-country cyclists. The aim of this study was to examine the physiological profile of youth national-level cross-country cyclists and to determine those variables that were able to best predict the performance in an official race. Ten youth cross-country cyclists of a national team underwent a complete evaluation that included anthropometric assessments, laboratory tests to evaluate the wattage at blood lactate thresholds and at maximal oxygen uptake $\left(\mathrm{PO}_{\mathrm{VO} \max }\right)$, and field tests to make an in-depth power profile of the athletes. The data obtained in the abovementioned tests was analysed along with total and partial race times during a competition belonging to the Union Cycliste Internationale (UCI) calendar. In the present study, large and statistically significant correlations $(\mathrm{r}=-0.67$ to $-0.95, p \leq 0.05)$ were found between maximal and submaximal indices of aerobic fitness and cycling performance, especially when they were normalised to body mass. A multiple regression analysis demonstrated that the wattage at $2 \mathrm{mmol} / \mathrm{L}, 4 \mathrm{mmol} / \mathrm{L}$ and $\mathrm{PO}_{\mathrm{VO} 2 \mathrm{max}}$ were able to explain $82 \%$ of the variance in total race time. In summary, the results of this study support the use of maximal and submaximal indices of aerobic power as predictors of performance in youth cross-country cyclists.
\end{abstract}

Keywords: cycling; youth; power profile; anthropometry; race performance

\section{Introduction}

Cross-country mountain bike competitions are one of the most challenging events at the elite level due to the high demands imposed on both the aerobic and anaerobic systems of energy [1-3]. Elite male cross-country cyclists have average levels of maximal oxygen uptake $\left(\mathrm{VO}_{2 \max }\right)$ of around $66-78 \mathrm{~mL} / \mathrm{kg} / \mathrm{min}$ and power output values at $\mathrm{VO}_{2 \max }$ of 358-426 W (5.5-6.4 W/ kg) [4-8], whereas females have average levels of $\mathrm{VO}_{2 \max }$ of $58-61 \mathrm{~mL} / \mathrm{kg} / \mathrm{min}$ and peak power output values of 280-320 W (4.5-5.9 W/kg) [9-11]. Some studies found correlations between aerobic and anaerobic fitness variables and performance in high-level cross-country cyclists, especially when such variables were normalised to body mass $[7,8,12]$. However, it seems that many factors are involved in mountain bike performance since, in some cases, single regression equations have not been able to explain more than $40 \%$ of the variance in race time [7]. Thus, predictive models with multiple regression analysis have been recently applied in order to predict performance from more than one prognostic variable $[1,13]$. This represents a better and more realistic approach in comparison with single regression models since they enable researchers to 
better understand the complexity of cross-country mountain biking by interconnecting the effect of multiple variables on the athlete's physiological response.

Since the emergence of the early studies that characterised the physiological responses to cross-country races $[5,10,14]$ and those that described cross-country cyclists' profiles $[6-8,11,12,15]$, the features of this discipline have changed dramatically. Nowadays, cross-country mountain bike races are shorter; they last about $90 \mathrm{~min}$ and cyclists compete in circuits of 4-6 km in length, instead of the longer circuits that were employed a few years back. Additionally, the circuits are riddled with technical sections with a variety of terrains, jumps, climbs, technical descents, rock gardens, etc., and this requires a high command of technical skills [16]. Therefore, both practitioners and researchers need more data, not only about the physiological responses to cross-country cycling events but also about the physiological and performance profiles of successful cross-country cyclists. Such information will serve to improve talent identification and enhance both training methods and the overall cross-country mountain bike performance among cyclists. Recently, some valuable data have been collected from elite mountain bikers competing in international races $[3,16]$. However, up to date, there is a scarcity of studies conducted on youth cross-country cyclists. The aim of this study was to examine the physiological profile of national-level youth cross-country cyclists of the Argentine National Team and to determine those variables that were able to best predict performance in an official race.

\section{Materials and Methods}

\subsection{Participants}

Ten young cross-country cyclists from the Argentinian National Team (16.3 \pm 0.95 years; $67.22 \pm 7.49 \mathrm{~kg} ; 176.74 \pm 4.23 \mathrm{~cm}$ ) volunteered to take part in this study. At that time, the Argentinian National Junior Team was composed of ten cyclists, and therefore, this sample represents the whole group of cyclists belonging to the National Team. By the time the study was conducted, all the athletes were competing in the Junior categories of National and International championships. In the sample, there were two National champions, and two of the cyclists were runners-up in the National championship. All participants had experience in mountain bike training and competition of at least 4 years. All the individuals, as well as their parents, were informed about the benefits and risks of the research and volunteered for this study by signing an informed consent document. Protocols were approved by the local ethics committee and were in accordance with the Declaration of Helsinki for research involving human subjects.

\subsection{Experimental Design}

This is a descriptive correlational study aimed at assessing the association between laboratory- and field-based physiological testing with race performance in cross-country youth cyclists. Participants underwent a battery of measurements during three separate days, having one day in between so as to guarantee an optimal recovery between sessions. During the first session, the cyclists were subjected to a physiological assessment in the field (i.e., a power profile test) at an ambient temperature of $25{ }^{\circ} \mathrm{C}$ and relative humidity of $65 \%$. The second and third sessions were carried out in an air-conditioned laboratory kept at $21{ }^{\circ} \mathrm{C}$ and relative humidity of $50 \%$. During the second session, the cyclists were subjected to a graded exercise test in order to determine power at different blood lactate thresholds. After $10 \mathrm{~min}$ of active recovery, the cyclists performed a graded exercise in order to determine their power at $\mathrm{VO}_{2 \max }$. Finally, the athletes underwent a third session in order to conduct a complete anthropometric assessment that was then followed by evaluations of lower-limb isometric and dynamic strength performance. A week after all the physiological assessments had been conducted, the athletes competed in a Union Cycliste Internationale (UCI) official mountain bike competition ( $15.6 \mathrm{~km}, 638 \mathrm{~m}$ of cumulative elevation gain), and their performance was recorded for subsequent analyses and comparisons. 


\subsection{Experimental Procedures}

\subsubsection{Pre-Experimental Standardisations}

The day before the experimental sessions, participants were encouraged to avoid strenuous exercise and ingestion of stimulants (e.g., caffeine) and to sleep for at least $8 \mathrm{~h}$. Fluid and diet guidelines $[17,18]$ were given to comply with before testing to ensure carbohydrate bioavailability and euhydration. A self-selected precompetitive diet/fluid routine that fulfilled these guidelines were chosen by each cyclist before the first session, and it was replicated before the second session. On the day of each session, participants arrived at the laboratory between 10:00 and 13:00 $\mathrm{h}$ in a fed state ( $\sim 3 \mathrm{~h}$ after their last meal).

\subsubsection{Field Physiological Assessments}

In the first session, a power profile test protocol was performed in order to determine the highest power output the cyclists could maintain for a particular duration of effort in a controlled environment, in accordance with the Australian Institute of Sport [19]. For this test, participants used their own bikes, and it was performed on a flat circuit. In brief, the test started with a 5 min warm-up at $75-100 \mathrm{~W}$ with two sprints of $3 \mathrm{~s}$ at $70 \%-80 \%$ of peak power. Then, the cyclists performed single all-out efforts of $6,15,30$, and $60 \mathrm{~s}$ with active recovery periods at 50-100 W. Finally, the test ended with two endurance efforts of 5 and $10 \mathrm{~min}$, with an active recovery period at 50-100 W between them. During all these efforts, participants were encouraged to produce maximal wattage from the beginning to the end of the time established, and they were allowed to use their cycling gears to obtain an appropriate cadence. The power production and cadence (Edge 520 device plus Rally XC200 power meters, Garmin, Olathe, KS, USA) were recorded during the entire protocol with a sampling frequency of $1 \mathrm{~s}$. The mean power output of the $6 \mathrm{~s}, 30 \mathrm{~s}, 60 \mathrm{~s}, 5 \mathrm{~min}$, and 10 min duration exercises $\left(P_{\text {sprint }}, P_{30 s}, P_{1 \min }, P_{5 \min }\right.$, and $\left.P_{10 \min }\right)$ was collected and analysed with specific software (version 3.5, GoldenCheetah). Critical Power (CP) was calculated based on the mean power output values of the $60 \mathrm{~s}, 5 \mathrm{~min}$, and $10 \mathrm{~min}$ efforts. When the power output was plotted against time, the sustainable power output fell as a function of exercise duration, following an asymptotic function. This asymptote is called $\mathrm{CP}$, while the curvature of the power-time relationship represents the work capacity available above the $\mathrm{CP}$. The $\mathrm{CP}$ was calculated in accordance with the following formula [20]:

$$
\mathrm{P}=\mathrm{W}^{\prime} \times(1 / t)+\mathrm{CP}
$$

where $\mathrm{W}^{\prime}$ is the fixed amount of energy in $\mathrm{kJ}$ above Critical Power; $t$ is the time in seconds; $\mathrm{CP}$ is the Critical Power in watts.

\subsubsection{Laboratory Physiological Assessments}

In the second session, participants performed two laboratory tests, carried out with their own bikes placed on an electronic indoor bike trainer (CompuTrainer, RacerMate, Inc., New York, NY, USA) and with a mobile power-measuring device (PowerTap G3, CycleOps, Madison, WI, USA). Each instrument was used in compliance with the manufacturer's recommendations. In order to determine blood lactate thresholds, a graded exercise test was conducted first. At rest, a blood sample was obtained to assess baseline blood lactate concentration. Then, each cyclist performed a 10-min warm-up at $100 \mathrm{~W}$, and then the workload was set at $150 \mathrm{~W}$ for $10 \mathrm{~min}$. Afterwards, the load was increased by $25 \mathrm{~W}$ every $5 \mathrm{~min}$, with $1 \mathrm{~min}$ of passive recovery between stages, following previous recommendations [21]. Participants were instructed to maintain a self-selected cadence during the whole test (cadence for all cross-country cyclists was between 80 and $95 \mathrm{rpm}$ ). At the end of each stage, blood samples were obtained from the earlobe, and the blood lactate concentration was measured using a portable lactate analyzer (Lactate Plus Meter, Nova Biomedical, Waltham, MA, USA), which had been previously calibrated. A hyperaemic lotion (Finalgon, Boehringer Ingelheim, Ingelheim am Rhein, Germany) was used to facilitate obtaining the blood samples. The heart rate was continuously monitored during 
the test with a chest belt and a heart rate monitor (EDGE 520, Garmin, Olathe, KS, USA). To assess the athlete's perception of fatigue, a Rating of Perceived Exertion scale (Borg Scale 1-10 point) was used at the end of each stage. The test ended once an exponential increase in blood lactate concentration was detected or when lactate values exceeded $4 \mathrm{mmol} / \mathrm{L}$. The blood lactate values were analysed with Lactate-E software in order to determine the power at: Lactate Threshold $1\left(\mathrm{PO}_{\mathrm{LT1}}\right)$, Lactate Threshold $2\left(\mathrm{PO}_{\mathrm{LT} 2}\right)$, fixed blood lactate concentration of $2 \mathrm{mmol} / \mathrm{L}\left(\mathrm{PO}_{\mathrm{X} 2 \mathrm{mmol} / \mathrm{L}}\right)$, fixed blood lactate concentration of $4 \mathrm{mmol} / \mathrm{L}\left(\mathrm{PO}_{\mathrm{X} 4 \mathrm{mmol} / \mathrm{L}}\right)$, and the lactate threshold calculated by the $\mathrm{D}_{\max }$ method $\left(\mathrm{PO}_{\mathrm{Dmax}}\right)$ [22]. Briefly, the $\mathrm{PO}_{\mathrm{LT} 1}$ corresponds to the work rate preceding an increase in blood lactate concentration of $1 \mathrm{mmol} / \mathrm{L}$ above the concentration at baseline. $\mathrm{PO}_{\mathrm{LT} 2}$ represents the work rate corresponding to the point of maximum acceleration of the estimated underlying lactate curve (i.e., the maximum of the second derivative of the lactate curve). $\mathrm{PO}_{\text {Dmax }}$ corresponds to the work rate corresponding to the point that yields the maximum perpendicular from a line $\mathrm{L}$, joining the first and last lactate measurements to the estimated lactate curve [23].

After $10 \mathrm{~min}$ of active recovery at a power of $100 \mathrm{~W}$, the athletes performed a graded exercise in order to determine their power output at $\mathrm{VO}_{2 \max }\left(\mathrm{PO}_{\mathrm{VO} 2 \max }\right)$. The graded exercise started at two steps $(50 \mathrm{~W})$ below the power that produces a blood lactate concentration of $\sim 4 \mathrm{mmol} / \mathrm{L}$, and then the load was increased by $25 \mathrm{~W}$ every $1 \mathrm{~min}$, without recovery between stages. During this test, participants chose a self-selected cadence during the whole test. The test ended when volitional exhaustion was achieved or when power could not be maintained by the athlete any longer (i.e., cadence $<50 \mathrm{rpm}$ ). Both the total workload and the last completed stage were recorded to calculate maximal aerobic power in accordance with the equation by Kuipers et al. [24], as follows:

$$
\mathrm{PO}_{\mathrm{VO} 2 \mathrm{max}}=\mathrm{W}_{\mathrm{f}}+(t / 60 \times 25),
$$

where $\mathrm{W}_{\mathrm{f}}$ is the last completed workload in watts, and $t$ is the time of the uncompleted stage in seconds.

All the athletes were verbally encouraged to reach their maximal performance during the test. The test was considered valid when participants rated their perceived exertion to be higher than 9 on the 1-to-10 point Borg scale, and heart rate was higher than $80 \%$ of the age-adjusted estimate of maximal heart rate [25].

\subsubsection{Anthropometric Profile and Maximal Isometric Strength}

The anthropometric assessments were conducted in the third session by two Level 2 anthropometrists trained by the International Society for the Advancement of Kinanthropometry (ISAK), in accordance with the ISAK protocol [26]. Body composition was calculated by applying the five-way fractionation method, which partitions the body into five anatomically defined tissue masses: adipose, muscle, residual, skeletal and skin [27]. The fractional mass obtained from the five-way fractionation method was estimated from direct anthropometric measures and expressed in absolute $(\mathrm{kg})$ and relative $(\%$ of total body mass $)$ terms. The sum of six skinfolds index $(\Sigma 6 \mathrm{Skf}=$ triceps + subscapular + suprailliac + thigh calf + abdominal + medial calf) was also calculated. After the anthropometric measurements, the maximal isometric strength of the lower limbs was assessed by means of a unilateral knee extension exercise protocol, in accordance with Requena et al. [28]. The unilateral knee extension isometric force of the right and left legs was recorded with a standard calibrated strain-gauge transducer (WinLaborat, Buenos Aires, Argentina) mounted inside a metal frame, which was placed using a Velcro belt around the distal part of the ankle, above the malleoli. During the testing, the cyclists were asked to exert an isometric knee extension against the belt of the strain-gauge transducer as forcefully as possible for 2-3 s. The force-time curve was analysed on a personal computer, and the highest force value of the three maximal attempts was considered as the maximal isometric force. The dynamic strength performance of the lower limbs was assessed by means of a squat jump, in accordance with Jimenez-Reyes et al. [29]. In brief, the cyclists were asked to stand in a 
semi-squatting position on a contact mat (WinLaborat, Buenos Aires, Argentina) placed at ground level for each repetition. The knee angle of $90^{\circ}$ was previously determined with a handheld goniometer. On command, participants jumped vertically, extending their hips as fast and forcefully as possible to reach a full extension of $180^{\circ}$, while the trunk was kept as straight as possible. Their hands remained on their hips for the entire duration of the movement. Three attempts were performed with two minutes of recovery between them. The data were recorded for the analysis of vertical jump height based on flight time.

\subsubsection{Cross-Country Mountain Bike Competition}

The mountain bike competition consisted of four laps of $3.9 \mathrm{~km}$ length for a total of $15.6 \mathrm{~km}$ and $638 \mathrm{~m}$ of cumulative elevation gain. On the week before the race, all participants underwent a controlled tapering microcycle to enable a full recovery. Before the race, all the athletes carried out a 30-min warm-up in a cyclo-stimulator. All the athletes' bikes were of similar characteristics, with carbon frames and double suspension. During the race, the athletes were allowed to drink water and sports drink ad libitum. All the athletes consumed a sports gel ( $25 \mathrm{~g}$ carbohydrate $+50 \mathrm{mg}$ sodium) in each lap to standardize the intake of exogenous carbohydrates. The time to complete the race as well the time for each lap were recorded and used as performance variables.

\subsection{Statistical Analysis}

The values are expressed as means \pm standard deviation (SD) in absolute values and relative to body mass. For the correlation coefficient calculation, a Spearman's rho $(\rho)$ statistic and its $95 \%$ confidence intervals $(95 \% \mathrm{CI})$ were used since it is more robust and has been recommended when the data do not come from a bivariate normal distribution. The assumption of normality was verified using the Shapiro-Wilk test. For the multiple regression analysis, a typical model given by $\mathrm{y}=\mathrm{a}+\mathrm{b}_{1 \times 1}+\mathrm{b}_{2 \times 2}+\ldots \mathrm{b}_{\mathrm{n} \times \mathrm{n}}$ was used. All physiological variables with $p<0.05$ were included, and a regression model with backward elimination was used to filter out redundant variables. By using a threshold of 5 points in the variance inflation factor, we avoided multicollinearity. The variables that were retained in the final backward elimination model were then analysed with a multivariate regression model using forward selection. Collected data from all the sources and variables were exported to an R script and analysed with RStudio statistical software [30]. Statistical significance for all analyses was set at $p<0.05$.

\section{Results}

The cyclists' anthropometric, physiological, and strength profiles are shown in Tables 1 and 2.

None of the anthropometric variables or squat jump height or knee maximal isometric force correlated with race performance. However, a significant correlation between squat jump height and $\mathrm{P}_{\text {sprint }}(\rho=0.74, p<0.05,95 \% \mathrm{CI}[-0.14,1.00])$ was found. Aiming to predict race performance with a multiple regression model, we used all the physiological variables assessed in the laboratory and/or in the field and chose the variables that correlated with the total race time (all variables presented in $\mathrm{W} / \mathrm{kg}$ ): $\mathrm{PO}_{\mathrm{X} 2 \mathrm{mmol} / \mathrm{L}}$ $(\rho=-0.88, p<0.01,95 \%$ CI $[-1.00,-0.39]), \mathrm{PO}_{\mathrm{X} 4 \mathrm{mmol} / \mathrm{L}}(\rho=-0.95, p<0.001,95 \% \mathrm{CI}$ $[-1.00,-0.72]), \mathrm{PO}_{\mathrm{VO} 2 \max }(\rho=-0.92, p<0.001,95 \% \mathrm{CI}[-1.00,-0.52]), \mathrm{P}_{5 \min }(\rho=-0.67$, $p<0.05,95 \%$ CI $[-0.98,-0.10])$, and $\mathrm{P}_{10 \min }(\rho=-0.77, p<0.05,95 \%$ CI $[-1.00,-0.16])$, $\mathrm{PO}_{\text {Dmax }}(\rho=-0.78, p<0.01,95 \%$ CI $[-0.98,-0.26])$, and CP $(\rho=-0.68, p<0.05,95 \%$ CI $[-1.00,-0.04])$. Histograms of distribution frequency, linear regression curves, and rho correlation coefficients of the top-five variables that best correlated with race time are shown in Figure 1.

For the prediction of race performance, a multiple regression analysis was conducted to assess the overall contribution of physiological variables to the interindividual variability of the total race time. As a result, a significant regression equation was found $\left(\mathrm{F}_{(3,5)}=7.52\right.$, $p=0.03$ ), with an $R^{2}=0.82$. A participant's predicted total race time was equal to: 
Race time $(\min )=255.86-32.87 \times \mathrm{PO}_{\mathrm{VO} 2 \mathrm{max}}-51.18 \times \mathrm{PO} \times 4 \mathrm{mmol} / \mathrm{L}+60.77 \times \mathrm{PO} \times 2 \mathrm{mmol} / \mathrm{L}$.
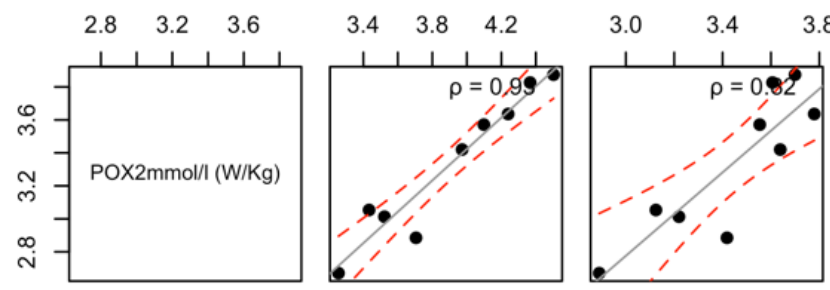

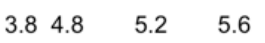
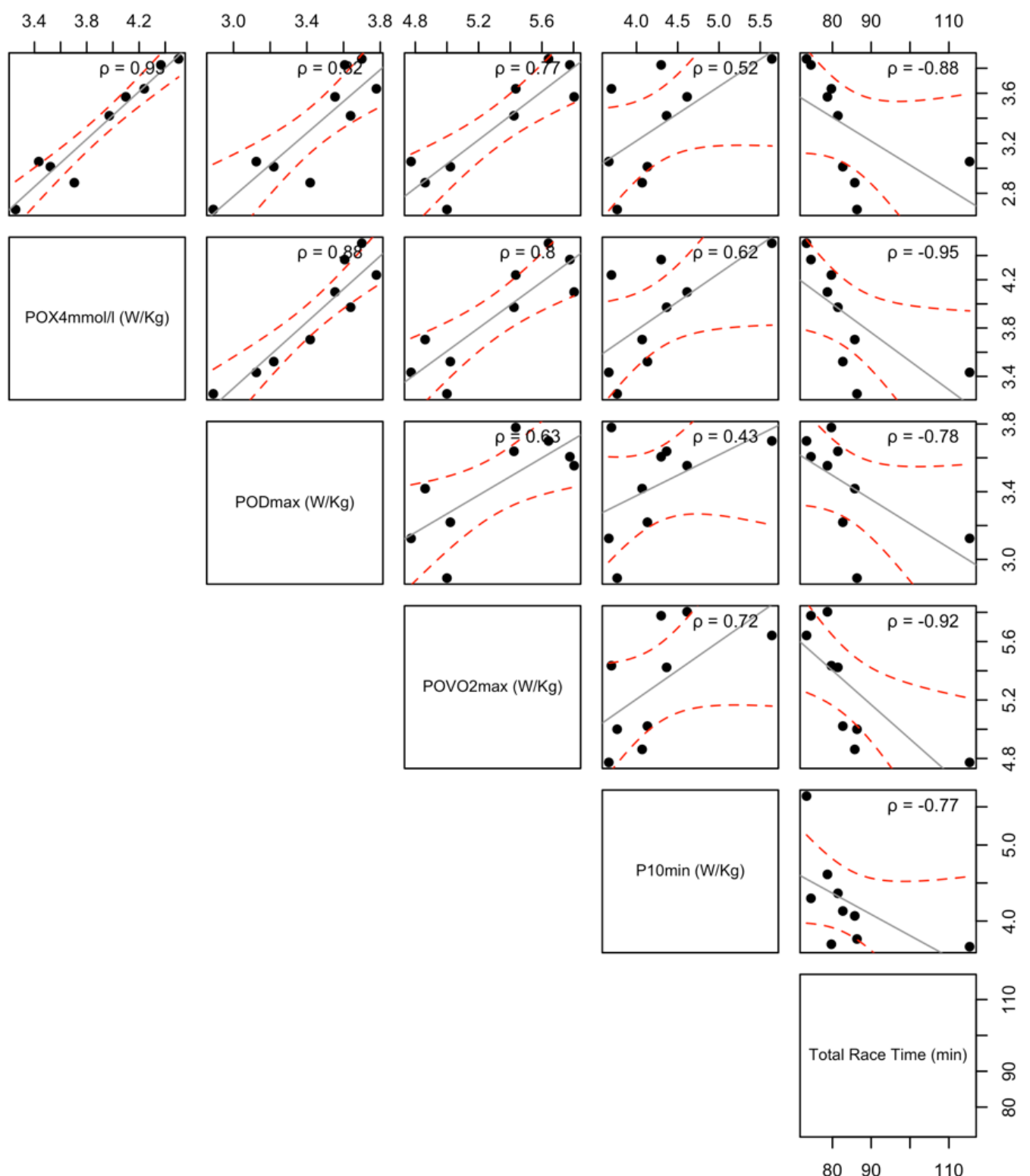

Figure 1. The correlation of the main physiological parameters and the total race time in elite youth cross-country cyclists.

Table 1. Anthropometric profile of elite youth cross-country cyclists.

\begin{tabular}{ccc}
\hline Variable (Units) & Absolute Values & Relative Values (\%) \\
\hline Age $(\mathrm{yr})$ & $16.3 \pm 0.95$ & - \\
Height $(\mathrm{cm})$ & $176.74 \pm 4.23$ & - \\
Body Mass $(\mathrm{kg})$ & $67.22 \pm 7.49$ & - \\
Muscle Mass $(\mathrm{kg})$ & $31.89 \pm 5.56$ & $47.25 \pm 3.24$ \\
Adipose Mass $(\mathrm{kg})$ & $15.26 \pm 1.43$ & $22.91 \pm 2.6$ \\
Bone Mass $(\mathrm{kg})$ & $9.11 \pm 1.28$ & $13.64 \pm 1.95$ \\
Residual Mass $(\mathrm{kg})$ & $7.3 \pm 1.17$ & $10.84 \pm 0.71$ \\
Skin Mass $(\mathrm{kg})$ & $3.75 \pm 0.26$ & $5.61 \pm 0.35$ \\
$\Sigma$ 6 Skinfolds $(\mathrm{mm})$ & $47.71 \pm 8.24$ & - \\
\hline
\end{tabular}


Table 2. Physiological and strength profile of elite youth cross-country cyclists.

\begin{tabular}{ccc}
\hline Variable (Units) & Absolute Values & $\begin{array}{c}\text { Normalised Values } \\
\text { (W/kg or N/kg) }\end{array}$ \\
\hline $\mathrm{PO}_{\mathrm{LT} 1}(\mathrm{~W})$ & $187.0 \pm 28.79$ & $2.79 \pm 0.41$ \\
$\mathrm{PO}_{\mathrm{LT} 2}(\mathrm{~W})$ & $232.75 \pm 29.54$ & $3.48 \pm 0.41$ \\
$\mathrm{PO}_{\mathrm{X} 2 \mathrm{mmol} / \mathrm{L}}(\mathrm{W})$ & $217.24 \pm 36.93$ & $3.24 \pm 0.49$ \\
$\mathrm{PO}_{\mathrm{X} \text { mmol } / \mathrm{L}}(\mathrm{W})$ & $258.34 \pm 32.4$ & $3.86 \pm 0.43$ \\
$\mathrm{PO}_{\mathrm{Dmax}}(\mathrm{W})$ & $228.44 \pm 21.96$ & $3.41 \pm 0.29$ \\
$\mathrm{PO}_{\mathrm{VO} \max }(\mathrm{W})$ & $354.6 \pm 37.81$ & $5.29 \pm 0.38$ \\
$\mathrm{CP}(\mathrm{W})$ & $262.9 \pm 53.79$ & $3.91 \pm 0.65$ \\
$\mathrm{P}_{10 \min }(\mathrm{W})$ & $286.9 \pm 50.97$ & $4.27 \pm 0.58$ \\
$\mathrm{P}_{5 \min }(\mathrm{W})$ & $319.2 \pm 50.1$ & $4.74 \pm 0.51$ \\
$\mathrm{P}_{1 \min }(\mathrm{W})$ & $499.3 \pm 49.76$ & $7.44 \pm 0.26$ \\
$\mathrm{P}_{30 \mathrm{~s}}(\mathrm{~W})$ & $704.1 \pm 117.09$ & $10.45 \pm 0.94$ \\
$\mathrm{P}_{\text {sprint }}(\mathrm{W})$ & $901.6 \pm 178.18$ & $13.52 \pm 2.8$ \\
Squat Jump $(\mathrm{cm})$ & $26.6 \pm 3.72$ & - \\
Right Knee Extension $(\mathrm{N})$ & $3827.1 \pm 900.3$ & $56.59 \pm 8.39$ \\
Left Knee Extension $(\mathrm{N})$ & $3274.6 \pm 1849.9$ & $60.34 \pm 7.74$ \\
Knee Extension Asymmetry $(\mathrm{N})$ & $493.8 \pm 389.2$ & $7.18 \pm 4.96$ \\
\hline
\end{tabular}

Values are means \pm SD. $\mathrm{PO}_{\mathrm{LT} 1}=$ power output at lactate threshold $1 ; \mathrm{PO}_{\mathrm{LT} 2}=$ power output at the lactate threshold 2; $\mathrm{PO}_{\mathrm{X} 2 \mathrm{mmol} / \mathrm{L}}=$ power output at a fixed blood lactate concentration of $2 \mathrm{mmol} / \mathrm{L} ; \mathrm{PO}_{X 4 \mathrm{mmol} / \mathrm{L}}=$ power output at a fixed blood lactate concentration of $4 \mathrm{mmol} / \mathrm{L} ; \mathrm{PO}_{\mathrm{Dmax}}=$ power output at a lactate threshold calculated by the $\mathrm{D}_{\max }$ method; $\mathrm{PO}_{\mathrm{VO} 2 \max }=$ power output at $\mathrm{VO}_{2 \max } ; \mathrm{CP}=$ critical power; $\mathrm{P}_{10 \min }=$ mean power output during a $10 \mathrm{~min}$ exercise; $\mathrm{P}_{5 \mathrm{~min}}=$ mean power output of a 5 min exercise; $\mathrm{P}_{1 \mathrm{~min}}=$ mean power output during a 1 min exercise; $\mathrm{P}_{30 \mathrm{~s}}=$ mean power output during a $30 \mathrm{~s}$ exercise; $\mathrm{P}_{\text {sprint }}=$ mean power output during a 6 s exercise.

\section{Discussion}

The main aim of this study was to examine the physiological profile of elite youth cross-country cyclists from a National Team and to determine those variables that were best able to predict performance in an official mountain bike race. In addition to this aim, the current study provides reference values on the physiological and anthropometric profiles of elite youth cross-country cyclists who compete at national and international levels. The most important finding of this study was that $82 \%$ of the variance in race time during an official competition could be predicted by using cycling power outputs at the lactate thresholds of 2 and $4 \mathrm{mmol} / \mathrm{L}$ and the power at $\mathrm{VO}_{2 \max }$. Interestingly, anthropometric variables and maximal lower limb performance measured by a squat jump and an isometric test did not correlate with race time. Collectively, all this information suggests that the use of maximal (power output at $\mathrm{VO}_{2 \max }$ ) and submaximal indices (power output at lactate thresholds) of aerobic performance may be used as fair predictors of performance in youth cross-country cyclists.

\subsection{Anthropometric Profile}

In order to contrast our results with those of other studies, we summarised the anthropometric profile of elite and young cross-country cyclists reported in previous studies (Table 3). The current study revealed that the anthropometric profile of our youth cyclists was similar to that of elite cross-country cyclists. In brief, the mean height of male elite mountain bikers is between $175-180 \mathrm{~cm}[2,4-8,10,11,31]$, and it was similar to our youth male cyclists' mean height, which was $177 \pm 4 \mathrm{~cm}$. The reported average body mass of elite and high-level cross-country male cyclists is between $65-72 \mathrm{~kg}[2,4-8,10,11,31]$. Our youth male athletes weighed $67 \pm 7 \mathrm{~kg}$, a value within the body mass range of high-level cross-country male cyclists. These data not only show the existence of a specific anthropometric profile of cross-country cyclists but also suggest that, in regard to elite cyclists, the anthropometric profile is already achieved at an early age. It is widely assumed that body composition is a very relevant factor in elite mountain bikers. In fact, an association has been suggested between body composition and competitive levels [2]. The average percent of body fat in elite mountain bikers is between $5.3 \%$ and 
$14.3 \%[6,8,31,32]$. However, our data show that elite youth cross-country cyclists have mean values of the adipose mass of $23 \pm 3 \%$, which is considerably higher. This is not surprising since adiposity values estimated through the five-way fractionation method derive from anatomically defined adipose tissue, as opposed to chemically defined fat mass estimated by traditional two-way fractionation methods [33]. Thus, whereas the five-way fractionation model evaluates adipose tissue (which comprises a lipid fraction, water, proteins, and electrolytes), the two-way fractionation models assess fat mass (which only includes the lipid fraction of adipose tissue) [34]. Indeed, when the five-way fractionation method was used to assess body composition in elite male and female youth triathletes, very similar values of adiposity to the ones reported here were observed [35]. Finally, to our knowledge, there are no studies that have conducted an in-depth anthropometric analysis of youth cross-country cyclists. In this regard, the present work aims to provide reference values of muscle, bone, and adipose tissue masses as well as of the sum of six skinfolds to be used for training purposes. Last, it is relevant to note that, despite the assumed importance of body composition for mountain bike performance [2], none of the anthropometric variables correlated with race time. This suggests that, once the appropriate body composition has been achieved in young cross-country cyclists, small interindividual variations do not explain mountain bike performance.

\subsection{Physiological Profile}

Junior mountain bike competitions have a lap length of 4-6 km and an average climbing altitude of about 500-1000 m [3], which demands a significant contribution of aerobic metabolism to fulfil the energy requirements [2]. In fact, maximal and submaximal indices of aerobic capacity, such as $\mathrm{VO}_{2 \max }$ and peak power output at the lactate threshold, have been able to explain up to $80 \%$ of the variance in off-road cycling performance $[7,8]$. In the present study, large correlations ( $\rho=-0.67$ to -0.95 ) were found between physiological markers of aerobic fitness and cross-country cycling performance (Figure 1), as was observed in other studies involving competitive and top-level cross-country cyclists $[1,8,12,13]$. In accordance with previous reports, our results suggest that the relationship between physiological parameters derived from power profile tests and cross-country cycling performance is higher when the cycling power output is normalised to body mass. This highlights the importance of the power-to-weight ratio $(\mathrm{W} / \mathrm{kg})$ in endurance disciplines that are characterised by several climbs and descents. Taking the physiological variables that best correlated with the total race time, we performed a multiple regression analysis, aiming to predict the race performance in a UCI official competition. As a result, we found a significant regression equation that was able to explain $82 \%$ of the variance in performance from only three variables: $\mathrm{PO}_{\mathrm{X} 4 \mathrm{mmol} / \mathrm{L}}, \mathrm{PO}_{\mathrm{X} 2 \mathrm{mmol} / \mathrm{L}}$ and $\mathrm{PO}_{\mathrm{VO} 2 \mathrm{max}}$. These findings are not trivial since single regression models have shown that $\mathrm{VO}_{2 \max }$ can only explain $20-40 \%$ of the variance in cross-country cycling performance $[7,8,15]$. Thus, it seems that performance in mountain biking depends not on single but rather on multiple physiological features. Thus, the combination of maximal aerobic fitness variables as well as aerobic-anaerobic transition variables may represent the best ones to predict cross-country race performance, at least in young cyclists. 


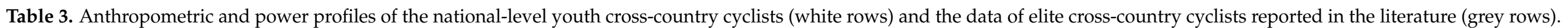

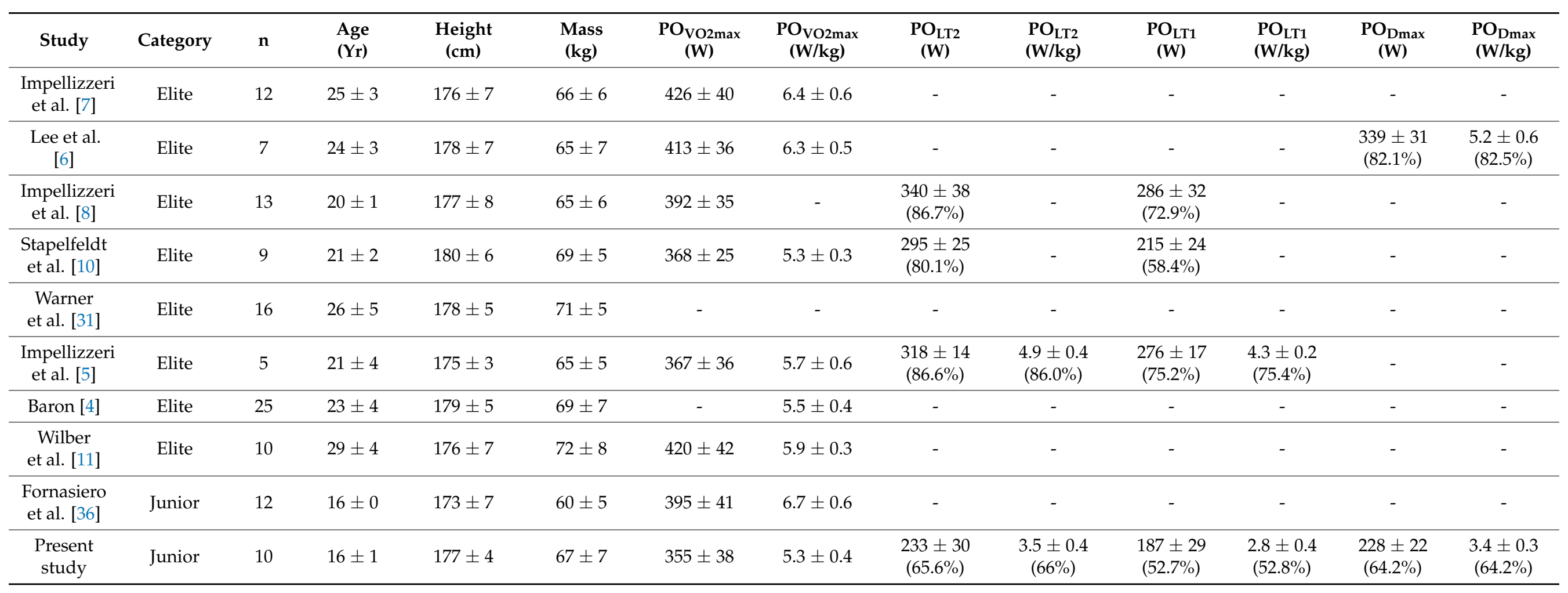


Finally, we compared the physiological profile of our cyclists with that of elite and young cross-country cyclists reported in previous studies (Table 3). According to our results, national-level youth cyclists have a suboptimal development of aerobic power and oxidative capacity compared to elite cross-country cyclists ( $>20$ years old). Specifically, the $\mathrm{PO}_{\mathrm{VO} 2 \mathrm{max}}(\mathrm{in} \mathrm{W} / \mathrm{kg}$ ) in our young cyclists was up to $17 \%$ lower than in elite cross-country cyclists $[4-8,10,11,31]$. In addition, the $\mathrm{PO}_{\mathrm{LT} 2}$ (in $\mathrm{W} / \mathrm{kg}$ ) was equivalent to $66 \%$ of the $\mathrm{PO}_{\mathrm{VO} 2 \mathrm{max}}$ in our cyclists, while this threshold corresponded to $80-87 \%$ of the $\mathrm{PO}_{\mathrm{VO} 2 \mathrm{max}}$ in elite cross-country cyclists $[5,8,10]$. We also compared our results with those of the study by Fornasiero et al. [36] in top-level young cross-country cyclists of the same age as our cyclists. ( 16 years old). We found that our young cyclists had a $21 \%$ lower $\mathrm{PO}_{\mathrm{VO} \text { max }}$ (in $\mathrm{W} / \mathrm{kg}$ ) than the Italian young cross-country cyclists. This might be explained by the fact that the athletes from the study by Fornasiero et al. were of a higher level than ours at that time. In fact, some of them were Youth Olympic and World Junior Champions, and their power profiles were even higher than that of elite cross-country cyclists.

\subsection{Strength Profile}

Most studies carried out on cross-country cyclists lack strength assessments, despite the fact that it is one of the most important variables in sports performance. In this respect, two recent studies performed multiple regression analyses and found that both handgrip strength and quadriceps femoris maximal torque were significant physiological determinants of cross-country cycling performance $[1,13]$. However, in the current study, none of the variables associated with the strength profile correlated with race time. In this study, we observed a significant correlation between the height obtained in a squat jump and $P_{\text {sprint. }}$. Thus, our results suggest that some lower-limb strength indices might act as independent predictors of short-duration maximal neuromuscular performance (i.e., $\mathrm{P}_{\text {sprint }}$ ) in youth cross-country cyclists, but it seemed that maximal jump height and maximal isometric strength in the lower limbs are not associated with mountain bike performance.

\subsection{Limitations}

Asides from its strengths, the current investigation presents some limitations that must be discussed so as not to affect the applicability of the results. First, the sample was composed of ten cyclists from the Argentinian National Junior Team of mountain biking. Although a higher sample size could have increased the statistical power of the study, the fact is that all the individuals of the National Team were recruited for the study. Further research with young cross-country cyclists from other National Teams may be required to confirm the importance of maximal and submaximal aerobic variables for overall mountain bike performance. Second, there were no measurements of ventilatory parameters such as $\mathrm{VO}_{2 \max }$ in the current investigation. This represents a limitation because this variable is a typical key indicator of mountain bike performance. However, we measured the $\mathrm{POVO}_{2 \text { max }}$, which is also a reliable indicator of maximal aerobic capacity. Lastly, there are other variables that may be associated with mountain bike performance during real competitions, such as cycling economy, anaerobic power and capacity, technical ability as well as pre- and in-competition nutritional strategies [2]. Therefore, future investigations should be carried out to determine the contribution of each one of these variables to overall mountain bike performance.

\section{Conclusions}

This study provides coaches with valuable information about reference values of body composition, physiological markers of aerobic fitness, and neuromuscular performance in top-level youth cross-country cyclists. However, the most important contribution of this study was that the combination of the values of cycling power output at $2 \mathrm{mmol} / \mathrm{L}$ and $4 \mathrm{mmol} / \mathrm{L}$ of the blood lactate concentration and the cycling power at $\mathrm{VO}_{2 \max }$ was able to explain $82 \%$ of the variance in total race time in a group of top-level youth crosscountry cyclists. In this regard, the results of this study support the use of maximal and 
submaximal indices of aerobic power and capacity as predictors of performance in youth populations who compete in mountain biking. These physiological parameters should be normalised according to body mass since this adjustment provides a better reflection of the athletes' performance capacity. Finally, we also recommend the use of lower-limb strength assessments (e.g., squat jump height) as markers of neuromuscular performance in short-duration maximal exercises in young cyclist populations, although their predictive value on the overall mountain bike performance seems to be limited.

Author Contributions: Conceptualization, G.G.M., R.M., L.M., F.A. and J.D.C.; methodology, G.G.M., R.M., L.M. and F.A.; formal analysis, G.G.M., R.M., L.M. and F.A.; writing-original draft preparation, G.G.M., R.M., L.M., F.A. and J.D.C.; writing-review and editing, G.G.M., R.M., L.M., F.A. and J.D.C. All authors have read and agreed to the published version of the manuscript.

Funding: This research received no external funding.

Institutional Review Board Statement: The study was conducted according to the guidelines of the Declaration of Helsinki and approved by the Institutional Review Board of the Universidad de Concepción del Uruguay, Argentina.

Informed Consent Statement: Informed consent was obtained from all subjects involved in the study.

Data Availability Statement: The data presented in this study are available on request from first author of this study.

Acknowledgments: We want to thank Melisa Bertola and Dario Linkowski for helping us with the data collection and the Federación Argentina de Ciclismo de Montaña (FACIMO) for supporting this study and allowing us to evaluate all the youth athletes from the National Team during a competitive period.

Conflicts of Interest: The authors declare no conflict of interest.

\section{References}

1. Bejder, J.; Bonne, T.C.; Nyberg, M.; Sjøberg, K.A.; Nordsborg, N.B. Physiological determinants of elite mountain bike cross-country Olympic performance. J. Sports Sci. 2019, 37, 1154-1161. [CrossRef] [PubMed]

2. Impellizzeri, F.M.; Marcora, S.M. The physiology of mountain biking. Sports Med. 2007, 37, 59-71. [CrossRef] [PubMed]

3. Hays, A.; Devys, S.; Bertin, D.; Marquet, L.-A.; Brisswalter, J. Understanding the Physiological Requirements of the Mountain Bike Cross-Country Olympic Race Format. Front. Physiol. 2018, 9, 1062. [CrossRef] [PubMed]

4. Baron, R. Aerobic and anaerobic power characteristics of off-road cyclists. Med. Sci. Sports Exerc. 2001, 33, 1387-1393. [CrossRef]

5. Impellizzeri, F.; Sassi, A.; Rodriguez-Alonso, M.; Mognoni, P.; Marcora, S. Exercise intensity during off-road cycling competitions. Med. Sci. Sports Exerc. 2002, 34, 1808-1813. [CrossRef]

6. Lee, H.; Martin, D.T.; Anson, J.M.; Grundy, D.; Hahn, A.G. Physiological characteristics of successful mountain bikers and professional road cyclists. J. Sports Sci. 2002, 20, 1001-1008. [CrossRef]

7. Impellizzeri, F.M.; Marcora, S.M.; Rampinini, E.; Mognoni, P.; Sassi, A. Correlations between physiological variables and performance in high level cross country off road cyclists. Br. J. Sports Med. 2005, 39, 747-751. [CrossRef]

8. Impellizzeri, F.M.; Rampinini, E.; Sassi, A.; Mognoni, P.; Marcora, S. Physiological correlates to off-road cycling performance. J. Sports Sci. 2005, 23, 41-47. [CrossRef] [PubMed]

9. Impellizzeri, F.M.; Ebert, T.; Sassi, A.; Menaspa, P.; Rampinini, E.; Martin, D.T. Level ground and uphill cycling ability in elite female mountain bikers and road cyclists. Eur. J. Appl. Physiol. 2008, 102, 335-341. [CrossRef]

10. Stapelfeldt, B.; Schwirtz, A.; Schumacher, Y.O.; Hillebrecht, M. Workload demands in mountain bike racing. Int. J. Sports Med. 2004, 25, 294-300. [CrossRef]

11. Wilber, R.L.; Zawadzki, K.M.; Kearney, J.T.; Shannon, M.P.; Disalvo, D. Physiological profiles of elite off-road and road cyclists. Med. Sci. Sports Exerc. 1997, 29, 1090-1094. [CrossRef] [PubMed]

12. Prins, L.; Terblanche, E.; Myburgh, K. Field and laboratory correlates of performance in competitive cross-country mountain bikers. J. Sports Sci. 2007, 25, 927-935. [CrossRef]

13. Novak, A.; Bennett, K.; Fransen, J.; Dascombe, B. A multidimensional approach to performance prediction in Olympic distance cross-country mountain bikers. J. Sports Sci. 2017, 36. [CrossRef]

14. Atkinson, G.; Davison, R.; Jeukendrup, A.; Passfield, L. Science and cycling: Current knowledge and future directions for research. J. Sports Sci. 2003, 21, 767-787. [CrossRef]

15. Gregory, J.; Johns, D.P.; Walls, J.T. Relative vs. absolute physiological measures as predictors of mountain bike cross-country race performance. J. Strength Cond. Res. 2007, 21, 17-22. [CrossRef] [PubMed] 
16. Granier, C.; Abbiss, C.; Aubry, A.; Vauchez, Y.; Dorel, S.; Hausswirth, C.; Meur, Y. Power Output and Pacing During International Cross-Country Mountain Bike Cycling. Int. J. Sports Physiol. Perform. 2018, 13, 1-22. [CrossRef] [PubMed]

17. Burke, L.M.; Hawley, J.A.; Wong, S.H.S.; Jeukendrup, A.E. Carbohydrates for training and competition. J. Sports Sci. 2011, 29, S17-S27. [CrossRef]

18. McDermott, B.P.; Anderson, S.A.; Armstrong, L.E.; Casa, D.J.; Cheuvront, S.N.; Cooper, L.; Kenney, W.L.; O'Connor, F.G.; Roberts, W.O. National Athletic Trainers' Association Position Statement: Fluid Replacement for the Physically Active. J. Athl. Train. 2017, 52, 877-895. [CrossRef]

19. Tanner, R.K.; Gore, C.J.; Sport, A.I.O. Physiological Tests for Elite Athletes, 2nd ed.; Human Kinetics: Champaign, IL, USA, 2012.

20. Jones, A.M.; Vanhatalo, A. The 'Critical Power' Concept: Applications to Sports Performance with a Focus on Intermittent High-Intensity Exercise. Sports Med. 2017, 47, 65-78. [CrossRef]

21. Tanner, R.K.; Gore, C.J.; Sport, A.I.O. Physiological Tests for Elite Athletes; Human Kinetics: Champaign, IL, USA, 2013.

22. Newell, J.; Higgins, D.; Madden, N.; Cruickshank, J.; Einbeck, J.; McMillan, K.; McDonald, R. Software for calculating blood lactate endurance markers. J. Sports Sci. 2007, 25, 1403-1409. [CrossRef]

23. Cheng, B.; Kuipers, H.; Snyder, A.C.; Keizer, H.A.; Jeukendrup, A.; Hesselink, M. A new approach for the determination of ventilatory and lactate thresholds. Int. J. Sports Med. 1992, 13, 518-522. [CrossRef] [PubMed]

24. Kuipers, H.; Verstappen, F.T.; Keizer, H.A.; Geurten, P.; van Kranenburg, G. Variability of aerobic performance in the laboratory and its physiologic correlates. Int. J. Sports Med. 1985, 6, 197-201. [CrossRef] [PubMed]

25. Edvardsen, E.; Hem, E.; Anderssen, S.A. End Criteria for Reaching Maximal Oxygen Uptake Must Be Strict and Adjusted to Sex and Age: A Cross-Sectional Study. PLoS ONE 2014, 9, e85276. [CrossRef] [PubMed]

26. Stewart, A.; Marfell-Jones, M.; Olds, T.; De Ridder, J. International Standards for Anthropometric Assessment; International Society for the Advancement of Kinanthropometry: Underdale, SA, Australia, 2011; Volume 137.

27. Kerr, D.A. An Anthropometric Method for Fractionation of Skin, Adipose, Bone, Muscle and Residual Tissue Masses in Males and Females Age 6 to 77 Years. Ph.D. Thesis, School of Kinesiology, Simon Fraser University, Burnaby, BC, Canada, 1988.

28. Requena, B.; Gonzalez-Badillo, J.J.; de Villareal, E.S.; Ereline, J.; Garcia, I.; Gapeyeva, H.; Paasuke, M. Functional performance, maximal strength, and power characteristics in isometric and dynamic actions of lower extremities in soccer players. J. Strength Cond. Res. 2009, 23, 1391-1401. [CrossRef] [PubMed]

29. Jimenez-Reyes, P.; Blanco, F.; Rodriguez Rosell, D.; Marques, M.; Badillo, J.J. Maximal Velocity as Discriminating Factor in Loaded Squat Jump Performance. Int. J. Sports Physiol. Perform. 2015, 11, 227-234. [CrossRef] [PubMed]

30. R Core Team. R: A Language and Environment for Statistical Computing. R Foundation for Statistical Computing. Available online: https: / / www.R-project.org/ (accessed on 20 May 2021).

31. Warner, S.E.; Shaw, J.M.; Dalsky, G.P. Bone mineral density of competitive male mountain and road cyclists. Bone 2002, 30, 281-286. [CrossRef]

32. Wingo, J.E.; Casa, D.J.; Berger, E.M.; Dellis, W.O.; Knight, J.C.; McClung, J.M. Influence of a Pre-Exercise Glycerol Hydration Beverage on Performance and Physiologic Function During Mountain-Bike Races in the Heat. J. Athl. Train 2004, 39, 169-175. [PubMed]

33. Holway, F.; Garavaglia, R. Kinanthropometry of Group I rugby players in Buenos Aires, Argentina. J. Sports Sci. 2009, 27, 1211-1220. [CrossRef]

34. Martin, A.D.; Daniel, M.Z.; Drinkwater, D.T.; Clarys, J.P. Adipose tissue density, estimated adipose lipid fraction and whole body adiposity in male cadavers. Int. J. Obes. Relat. Metab. Disord. 1994, 18, 79-83. [CrossRef]

35. Landers, G.; Blanksby, B.; Ackland, T.; Smith, D. Kinanthropometric differences between World Championship senior and junior elite triathletes. In Proceedings of the Proceedings from the Gatorade International Triathlon Science II Conference, Noosa, Australia, 7-8 November 1999; pp. 74-87.

36. Fornasiero, A.; Savoldelli, A.; Modena, R.; Boccia, G.; Pellegrini, B.; Schena, F. Physiological and anthropometric characteristics of top-level youth cross-country cyclists. J. Sports Sci. 2018, 36, 901-906. [CrossRef] 